УДК 331.55

DOI: $10.17223 / 19988648 / 44 / 9$

\title{
Н.3. Сотников
}

\section{ДИАЛЕКТИКА ДЕЛОВОЙ КАРЬЕРЫ БАНКОВСКИХ РАБОТНИКОВ: СОЦИАЛЬНО-ЭКОНОМИЧЕСКИЙ МОДУС}

\begin{abstract}
В статье рассматриваются результаты научных изысканий проиессов формирования, развития и разрушения деловой карьеры в банковских организачиях г. Новосибирска в период 2010-2016 г2. Гипотеза исследования состоит в том, что сочиально-экономический модус деловой карьеры определяет механизмы локализации и утверждения конкурентного превосходства как работника, так и банковской организации в рыночной ситуации. Познание социальноэкономического модуса деловой карьеры банковских работников позволило выявить стратегические альтернативы деловой карьеры.

Ключевые слова: деловая карьера, социально-экономический модус, банковский персонал, конкурентоспособность персонала, интенсивность карьеры.
\end{abstract}

Вектор реиндустриализации российской экономики связан со сменой парадигмы развития банковского сектора: от стремления расширять банковский бизнес за счет агрессивных маркетинговых технологий к повышению качества банковских активов, от продукто- к клиентоориентированной идеологии. В условиях возрастания роли знаний в банковском бизнесе, который все больше базируется на идеях и брендах, коренная трансформация ценностей, мировоззренческих и идеологических установок выдвигает на первый план важнейшую экономическую проблему формирования конкурентоспособного персонала коммерческого банка. Без профессионально подготовленного и лояльного персонала невозможно повысить качество активов, сократить масштаб сомнительных операций проблемных банков в короткие сроки на фоне нестабильной экономической ситуации, не допустить полномасштабного кризиса доверия.

В условиях высокой сложности, неопределенности и динамичности окружающей социально-экономической среды, становления «прозрачного» мирового рынка традиционные методы повышения эффективности труда такие, как рационализация и автоматизация бизнес-процессов, поиск талантов (охота «за головами»), зачастую не приводят к повышению конкурентоспособности человеческих ресурсов. Для того чтобы быть конкурентным в этой среде, необходимо создание условий для постоянного стремления работника к осознанному формированию долгосрочного превосходства над работниками-конкурентами, преумножения его конкурентных компетенций посредством деловой карьеры.

Для теоретико-методического осмысления механизма формирования конкурентоспособности банковского персонала первостепенное значение 
имеет познание параметров состояния и характеристик социальноэкономического модуса деловой карьеры, который позволит сформировать стратегический потенциал рынка труда банковского сектора.

Деловая карьера работника как объект изучения находится в центре внимания советской, российской и зарубежной науки не один десяток лет. Интерес к изучению этого процесса, его масштабов, интенсивности и факторов не случаен, поскольку в нем наиболее ярко выражаются многие важные процессы социальной мобильности рабочей силы, которые происходят постоянно и отражают динамизм рынка труда.

Деловая карьера в литературе рассматривается как комплексная, открытая и целостная система, представляющая высшую степень единства взаимосвязанных между собой трех субстанций.

Во-первых, деловая карьера предстает как фактор достижения личных успехов и опережения других работников-конкурентов, стремящихся к идентичным целям [1]. Результатом достижения личных успехов и опережения работников-конкурентов в потоке социальной жизни является сохранение достигнутого работником качества трудовой жизни и возвышение его, сопряженное «с увеличением заработной платы, уровнем должностных прав и обязанностей, степенью самостоятельности и ответственности» [2. С. 54].

Во-вторых, деловая карьера предстает как функция социальной мобильности [3-7]. Социальная мобильность проявляется как «системное явление, отражающее объективную сторону процесса социализации индивида (содержание и направления социально-экономической, образовательной, культурной политики, а также функции, принципы, задачи в управлении обществом, законодательные, нормативно-правовые, организационные, поведенческие и иные условия социального бытия) и субъективную (комплекс основных личностных качеств, также определяющих содержание и направление социальной мобильности)» [8. С. 93].

В-третьих, деловая карьера предстает как деятельность по позиционированию работника в иерархической стратифицированной системе разделения труда [9; 10. С. 11-13]. Позиционирование на рынке труда может быть как личностно-профессиональным, т.е. локализация (фиксация) и закрепление определенного статуса (положения) и роли работника в профессиональной сфере деятельности в соответствии с его знаниями, умениями, навыками, установками; так и статусно-дол-жностным, т.е. обретение социальных и материальных достижений в конкретных внеорганизационной и внутриорганизационной реальностях, воспринимаемое как объективная серия статусов и четко определенных должностей, ролей, состояний материального благополучия и т.п. [14-16]. Позиционирование позволяет работнику получить личностно-значимые выгоды в различных жизненных и трудовых ситуациях через систему социальных отношений (т.е. прав, обязанностей и ответственности) в изменяющихся условиях рыночного разделения труда. 
Итак, деловая карьера представляет процесс конкурентного позиционирования работника в рыночной системе разделения труда, способствующий сохранению или улучшению качества трудовой жизни на основе социальной мобильности в изменяющихся условиях внутри- и внеорганизационной реальностей.

Карьера работников коммерческого банка осуществляется в экономически, социально и психологически непростых, жестко формализованных условиях. Основанием для карьеры, перемещений в карьерном пространстве являются единые официально и неофициально принятые в конкретном банке требования для достижения определенных ступеней профессионально-должностного ряда. Содержание оснований для карьеры обусловлено необходимостью наиболее полного удовлетворения рыночной потребности в труде, преумножения интеллектуального капитала банковской организации и защиты бизнес-деятельности от стагнации.

Официальными основаниями для деловой карьеры являются требования квалификационного лицензирования профессии банковского работника, предусматривающие защиту работодателя от некомпетентных наемных работников. Они формализованы и жестко структурированы. Это официальные формальные квалификации, предполагающие наличие специфических навыков и компетенций, которые в принципе не могут быть реализованы за пределами банковского сектора; достаточные действительные квалификации, подтвержденные опытом банковской работы; специальный профессиональный язык и специфический способ восприятия реальности; обязательная последовательность в прохождении работником всех уровней служебно-должностной иерархии, предусматривающая динамику объема и роли организационных, оперативных и стратегических функций профессиональной деятельности.

Неофициальные основания для карьеры банковского работника представляют собой принятые в конкретном банке морально-этические принципы, нормы и правила человеческих взаимоотношений относительно личностно-профессионального и статусно-должностного позиционирования, согласующиеся с социокультурным этносом и кадровой политикой организации, политикой Центрального банка РФ. Эти основания формируются под влиянием, как правило, закрытого типа корпоративной культуры банка и транслируются через формирование сети филиалов и отделений по территориальному принципу.

В рамках научных изысканий процессов формирования, развития и разрушения деловой карьеры было проведено маркетинговое исследование ее социально-экономического модуса в банковских организациях г. Новосибирска в период 2010-2016 гг., результаты которого представляются репрезентативными для понимания исследуемого феномена. Целью исследования является познание социально-экономических закономерностей деловой карьеры в зависимости от конкурентной позиции банковских организаций на рынке труда. Исследование модуса деловой карьеры призвано идентифицировать и прогнозировать благоприятные возможности и опас- 
ности, которые могут возникнуть при достижении конкурентного превосходства работников и банковских организаций на рынке труда в целях наиболее полного удовлетворения их социально различных интересов в качестве трудовой жизни.

Как показало проведенное исследование, осознание социальноэкономического модуса деловой карьеры у каждого работника происходит через призму целей, желаний, установок, связанных с его трудовым опытом и деятельностью вне работы: оно сугубо личное, зависящее от специфики личной жизни и профессиональной деятельности (табл. 1).

Таблица 1. Распределение ответов на вопрос «Какой смысл вы вкладываете в понятие “деловая карьера"?» (\% работников, которые отметили данный ответ)*

\begin{tabular}{|c|c|}
\hline Деловая карьера - это... & Доля ответов, \% \\
\hline $\begin{array}{l}\text { Достижение достойного и повышение материального благополучия } \\
\text { для себя и своих близких }\end{array}$ & 67,8 \\
\hline $\begin{array}{l}\text { Обладание комфортными условиями труда (работа в чистой здоровой } \\
\text { обстановке, а также наличие кабинета, личного автомобиля и т.п.) }\end{array}$ & 40,5 \\
\hline $\begin{array}{l}\text { Формирование благоприятных межличностных отношений с руко- } \\
\text { водителями, коллегами, подчиненными }\end{array}$ & 44,7 \\
\hline Уважение и известность в организации & 53,4 \\
\hline Процесс профессионального роста компетентности работника & 57,8 \\
\hline $\begin{array}{l}\text { Достижение успеха, видного положения в обществе, на служебном } \\
\text { поприще }\end{array}$ & 68,3 \\
\hline Достижение превосходства над другими людьми & 70,1 \\
\hline Работа не по стандарту, творчески, создание нового & 45,4 \\
\hline $\begin{array}{l}\text { Развитие работника, которое не вступает в противоречие с его сти- } \\
\text { лем жизни }\end{array}$ & 43,2 \\
\hline $\begin{array}{l}\text { Деятельность, которая в полной мере позволяет реализовать трудо- } \\
\text { вой потенциал }\end{array}$ & 55,6 \\
\hline Признание заслуг в труде & 52,1 \\
\hline Гарантия постоянной работы, стабильность положения & 44,6 \\
\hline
\end{tabular}

* Разработано автором.

Для большинства банковских работников карьера - это процесс служебно-должностного позиционирования в организационной реальности: достижение превосходства над другими людьми (70,1\%), путь к успеху, видному положению в обществе, на служебном поприще $(68,3 \%)$, признание заслуг в труде $(52,1 \%)$.

Не менее характерно для банковских работников восприятие карьеры как личностно-профессионального позиционирования в организационной среде: профессиональный рост компетентности работника $(57,8 \%)$, который не вступает в противоречие с его стилем жизни $(43,2 \%)$ с тем, чтобы осуществлять профессиональную деятельность не по стандарту, творчески, создавать новое $(45,4 \%)$, в полной мере реализовывать трудовой потенциал $(55,6 \%)$ и повышать свою ценность и репутацию в организации $(53,4 \%)$.

Карьера для работника нередко воспринимается и как способ удовлетворения меркантильных потребностей типа достижения материального 
благополучия (67,8\%), улучшения условий труда (40,5\%), формирования благоприятных межличностных отношений в трудовом коллективе $(44,7 \%)$, гарантий постоянной работы и стабильности положения (44,6\%).

Не трудно заметить, что социально-экономический модус карьеры связан с достижением неких личных успехов в виде более или менее четко определенных позиций, должностей, статусов, ролей, воспринимаемых как результат сохранения или улучшения качества трудовой жизни посредством обретения чувства превосходства над другими работниками. При этом существуют различия в понимании модуса деловой карьеры у работников в зависимости от организационной стратегии (табл. 2).

Таблица 2. Различия в понимании смысла деловой карьеры работниками банковских организаций с различными стратегиями развития (по результатам анкетирования банковских работников), \% от общей численности респондентов *

\begin{tabular}{|l|c|c|c|}
\hline \multirow{2}{*}{ Тип стратегии } & \multicolumn{3}{|c|}{ Деловая карьера-это } \\
\cline { 2 - 4 } & $\begin{array}{c}\text { служебно- } \\
\text { должностное пози- } \\
\text { ционирование }\end{array}$ & $\begin{array}{c}\text { личностно- } \\
\text { профессиональное } \\
\text { позиционирование }\end{array}$ & $\begin{array}{c}\text { удовлетворение } \\
\text { меркантильных } \\
\text { потребностей }\end{array}$ \\
\hline Предпринимательская & 18 & 61 & 21 \\
\hline Прибыльности & 28 & 25 & 47 \\
\hline Динамического роста & 67 & 22 & 11 \\
\hline Циклическая & 24 & 54 & 22 \\
\hline Ликвидационная & 25 & 23 & 52 \\
\hline
\end{tabular}

* Разработано автором.

Так, наиболее часто работниками в банках со стратегией динамического роста карьера рассматривается в контексте служебно-должностного позиционирования (67\%). Для этих работников карьера предстает как серия переходов с одного рабочего места (должностной позиции) на другое, способствующих динамике влияния, власти, авторитета, статуса в организационной среде. Продвижение по службе, расширение функционала в организации гармонизируются и ускоряются посредством обучения новым технологиям, переквалификации и подготовки к старту новой карьеры.

Занятыми в банках с предпринимательской (61\%) и циклической (54\%) стратегиями карьера рассматривается как овладение разнообразными навыками, компетенциями, дополняющими и развивающими их, т.е. карьерная траектория напрямую связана с личностно-профессиональным позиционированием. Зачастую эти работники «зацикливаются» на обучающем аспекте карьеры и совершают одну и ту же типичную ошибку, рассматривая обучение как самоцель, а не как инструмент для совершенствования внутриорганизационного позиционирования и повышения своей конкурентоспособности.

Работники в банках со стратегией прибыльности (47\%) и ликвидационной стратегией (52\%) нередко воспринимают карьеру как способ защитить собственный статус и доходы, связанные с выполняемой деятельностью в организации. Эти сотрудники вполне лояльны к организации, но проблема 
заключается в том, что велик риск достижения ими так называемого «плато карьеры» или «карьерного дауншифтинга», когда сотрудники профессионально «перерастают» свои должностные позиции.

Итак, социально-экономический модус деловой карьеры, описывая стратегические альтернативы улучшения конкурентных позиций на рынке труда, предстает как целостная система элементов позиционирования работником себя в потоке социальной жизни, обеспечивающего ему локализацию и утверждение конкурентного превосходства посредством, во-первых, механизма профессиональной карьеры работника, создающего условия для профессионального развития и предполагающего непрерывное воспроизводство конкурентных преимуществ на протяжении рабочей жизни каждого работника. Во-вторых, механизма организационной карьеры, связанного со служебнодолжностным позиционированием конкурентных преимуществ работника в стратифицированной системе разделения труда с учетом внутри- и внеорганизационной реальностей. Социально-экономический модус деловой карьеры в банках призван синхронизировать профессиональную и организационную карьеру с целью защиты банковской деятельности от застоя.

Характерной особенностью модуса деловой карьеры банковских работников является то, что интенсивность профессиональной карьеры выше интенсивности организационной при всех стратегиях развития банков, за исключением ликвидационной (табл. 3). Следует заметить, ситуация при ликвидационной стратегии развития банка оправданна, поскольку связана с постепенной утратой конкурентных позиций организацией на рынке труда, а следовательно, ухудшением важнейших социально-экономических показателей ее деятельности.

Организационная карьера представляет собой диалектическое единство межорганизационной и внутриорганизационной.

Межорганизационная карьера предполагает перемену рабочего места, сопровождаемую переходом работника из одной организации (филиала) в другую, связанным с изменением либо профессиональной позиции работника, либо его должностной позиции, либо уровня конкурентоспособности самой организации, либо ее территориального расположения [17]. Эта карьера, с одной стороны, расширяет возможности банка-работодателя в привлечении работников, овладевших разнообразными навыками, компетенциями и обладающих конкурентными преимуществами, а с другой позволяет самим работникам в полной мере реализовать свои конкурентные преимущества не в рамках одной организационной лестницы, а путем серии перемещений между рабочими местами разных филиалов, структурных подразделений банковских организаций.

Внутриорганизационная карьера включает последовательность важнейших перемен труда работником в стратифицированной системе трудовой деятельности в банковской организации. Это серия переходов работника с одного рабочего места на другое внутри организации. Внутриорганизационное направление карьеры характеризуется неопределенностью и многообразием, связанным с различными статусами его участников, со специфически- 
ми социально-экономическими интересами каждого из них, неоднозначностью их поведения, многоаспектностью их функционирования.

\section{Таблица 3. Стратегия деловой карьеры в зависимости от ее интенсивности: матрица «стратегия - карьера» (на примере банковских организаций г. Новосибирска)*}

\begin{tabular}{|c|c|c|c|c|c|}
\hline \multirow{2}{*}{$\begin{array}{l}\text { Организаци- } \\
\text { онная страте- } \\
\text { гия развития }\end{array}$} & \multicolumn{5}{|c|}{ Интенсивность деловой карьеры кадров $s=\left(s^{\text {out }} ; s^{\text {in }} ; s^{p}\right)$} \\
\hline & $\begin{array}{c}\text { доминирующий } \\
1<s^{p}<s^{o}\end{array}$ & $\begin{array}{c}\text { высокий } \\
{ }_{s}^{p}<s^{o} \leq 1\end{array}$ & $\begin{array}{c}\text { естественный } \\
s^{o}=s^{p}\end{array}$ & $\begin{array}{c}\text { благоприят- } \\
\text { ствующий } \\
s^{o}<s^{p} \leq 1\end{array}$ & $\begin{array}{c}\text { благопри- } \\
\text { ятный } \\
1<s^{o}<s^{p}\end{array}$ \\
\hline $\begin{array}{l}\text { Предприни- } \\
\text { мательская }\end{array}$ & & & & & $\begin{array}{c}(1,99 ; 0,04 ; \\
2,62)\end{array}$ \\
\hline $\begin{array}{l}\text { Динамиче- } \\
\text { ского роста }\end{array}$ & & & & & $\begin{array}{c}(0,2 ; 0,69 ; \\
1,21)\end{array}$ \\
\hline $\begin{array}{l}\text { Прибыльно- } \\
\text { сти }\end{array}$ & & & $\begin{array}{c}(0,58 ; 0,23, \\
0,83)\end{array}$ & & \\
\hline \begin{tabular}{|l} 
Ликвидаци- \\
онная \\
\end{tabular} & $(1,02 ; 0,34 ; 0,68)$ & & & & \\
\hline Циклическая & & & & $\begin{array}{c}(0,43 ; 0,42 \\
1,0)\end{array}$ & \\
\hline
\end{tabular}

Примечание. $s$ - интенсивность деловой карьеры; $s^{o}=\left(s^{\text {out }}+s^{\text {in }}\right)-$ интенсивность организационной карьеры; $s^{\text {out }}$ - интенсивность межорганизационной карьеры; $s^{\text {in }}$ интенсивность внутриорганизационной карьеры; $s^{p}-$ интенсивность профессиональной карьеры.

Область естественной деловой карьеры.

Область интенсивной деловой карьеры.

Область экстенсивной деловой карьеры.

* Разработано авторами.

Формирование, развитие и разрушение межорганизационной и внутриорганизационной карьеры, находясь во внутреннем единстве и взаимопроникновении, подчиняются разным закономерностям и поэтому не совпадают по времени и направлению изменений. Это приводит к особым ситуациям развертывания социально-экономического конфликта между этими видами организационной карьеры, способствующего изменению конкурентной позиции работников и банковских организаций на рынке труда (см. табл. 3).

Социально-экономический модус деловой карьеры при предпринимательской стратегии имеет ярко выраженную межорганизационную направленность и связан с переходом работника из одной банковской организации в другую с изменением либо организационного статуса, либо территориального расположения. Как правило, большинство работников (около 70\%) приходят в организацию с предпринимательской стратегией развития в возрасте до 30 лет, без опыта работы в банковской сфере, но с соответствующим желанием получить этот первичный опыт, запись в тру- 
довую книжку о стаже работы в кредитной организации, создать себе имя и репутацию. Иначе говоря, организационная карьера в этих организациях ориентирует сотрудника не столько на движение по административной лестнице, сколько на приобретение некоего субъективного профессионального опыта, расширение границ собственного восприятия мира и действительности, более полное удовлетворение потребностей в накоплении человеческого капитала и совершенствование своего профессионализма.

В этой связи внутриорганизационная карьера в таких организациях достаточно редка - всего около 10-15\% сотрудников имеют возможность ее реализовать, при этом преимущественно в дивизиональной форме. Для занятия более высокой должности в таких организациях в среднем необходимо отработать в организации 6-10 лет. Однако сотрудники не готовы ждать продвижения по службе такой срок. По этой причине они находятся в ожидании более значимой личностной выгоды, например получения перспективной работы с более высокой материальной компенсацией в другой организации, с более высоким статусом и т.П. Пик кривой выживаемости сотрудников в этих организациях приходится на 1,8 года работы в организации: 1/4 принятых увольняются в первые три месяца работы и спустя 3 года работы в организации их остается менее 5\%.

Уровень межорганизационной карьеры при цииклической стратегии самый низкий $(15,9-25,5 \%)$ в сравнении с масштабами при других организационных стратегиях развития. Этим видом карьеры охвачены, как правило, работники средней квалификации, в частности работники фронт-офиса. Профессионалы бэк-офиса из-за риска потерять достигнутый статус экспертной власти, полагаясь на возможности централизованного регулирования деловой ситуации, не спешат менять организацию, поскольку внутри своей организации они чувствуют себя более защищенными вследствие привычки, боязни потерять в зарплате, не найти лучшей работы и надеются на улучшение организационно-экономической ситуации.

В какой-то мере внутриорганизационная карьера в организациях с циклической стратегией, находясь в диапазоне 14,0-25,5\%, компенсирует негативные последствия низкой межорганизационной активности, способствуя «очищению» должностных позиций от неэффективных работников, открывая возможности для горизонтальной $(7,2-14,7 \%)$ и вертикальной (6,8-11,9\%) карьеры лояльных профессионалов. Работникам предоставляются возможности сменить подразделение, сферу профессиональной деятельности, осваивать новые профессиональные знания и навыки с тем, чтобы повысить их удовлетворенность трудом и лояльность к организации, а следовательно, максимизировать их вклад в достижение организационных целей. На фоне возникающих трудностей в заполнении вакантных должностей происходит снижение требований к компетенциям работников, увеличение риска экономических потерь.

Относительно более высокие, чем при циклической стратегии, возможности для карьерной активности имеются в банковских организациях со стратегией прибыльности (43,1-87,5\%). Карьерная активность банковско- 
го персонала в этих организациях характеризуется высокими возможностями для межорганизационной карьеры $(29,6-50,3 \%)$ и ограниченными для внутриорганизационной $(13,5-25,7 \%)$.

Другими словами, банковские организации со стратегией прибыльности имеют ограниченные возможности гарантировать всем квалифицированным работникам движение в организационной иерархии. Средний срок пребывания работника в одной должности находится в диапазоне 7,9-13,3 года, в одном подразделении - 7,6-16,6 года. Как следствие, 67\% сотрудников, имеющих стаж работы в организации более 5 лет, при низкой скорости внутриорганизационной карьеры профессионально «перерастают» свои должности (рабочие места), но перспектив роста нет, более высокие позиции заняты. В связи с этим усиливается влияние латентных негативных процессов деловой карьеры (плато карьеры, карьерный дауншифтинг).

Высокий уровень межорганизационной карьеры наблюдается при ликвидаџионной стратегии (50,3-67,0\%). Это объективно обусловлено необходимостью реорганизации трудового потенциала персонала в связи предстоящим прекращением деятельности банка.

Наиболее широкие возможности для внутриорганизационной карьерной активности существуют в организациях со стратегией динамического роcma (44,5-93,9\%). Общая модель внутриорганизационной карьеры в таком банке представляет собой лестницу, где подчеркнуто поступательное движение вверх в одной строго определенной функциональной сфере внутри конкретной организации в целом. Иначе говоря, банковский сотрудник имеет возможность развиваться преимущественно в рамках своего подразделения посредством выбора такой карьерной позиции, где его должность будет иметь более «высокое» название, чем название предыдущей должности. Долговременная занятость внутри такого банка выступает в качестве основного принципа управленческого и карьерного успеха.

Характерной особенностью внутриорганизационной карьерной активности в организациях со стратегией динамического роста является то, что в них с вертикальной и горизонтальной карьерой тесно сопряжена дивизиональная. Необходимость и возможность такой карьерной активности обусловлены тем, что банки, зачастую расположенные в крупных городах, имеют разветвленную сеть филиалов, разбросанных по территории страны.

Итак, деловая карьера выступает как диалектическая система, движущей силой и источником развития которой является возникновение, становление и разрешение внутренне присущего ей конфликта между профессиональной карьерой и организационной, межорганизационной и внутриорганизационной. Модус деловой карьеры описывает способ разрешения этого конфликта и ориентирован на сохранение или улучшение конкурентной позиции на рынке труда. При этом он ограничен и задан объективно существующими правилами и статусно-должностными предписаниями, характеризующими рыночную стратифицированную систему разделения банковского труда. Для банков с разными стратегиями развития он различен. 
Маркетинговый модус деловой карьеры характерен для банков со стратегией динамического роста. Этот модус ориентирован на диалектическое согласование возможностей для профессиональной и организационной карьеры: работник получает уникальную возможность реализовать свой потенциал и обогатить свой опыт и тем самым ускорить свое движение вверх по карьерной лестнице, а организация-работодатель минимизирует риск с назначением специалиста, который является носителем корпоративной культуры, успел себя зарекомендовать как ответственного и успешного, а следовательно, получить прогнозируемый результат от карьеры работника. Карьера рационально связана со стратегией бизнеса и строится при высокой значимости объективных критериев оценки профессионализма, качества образования работника, креативности и коммуникабельности.

Технократический модус деловой карьеры характерен для банков, придерживающихся ликвидационной стратегии развития. Он исходит из ориентации на интересы работодателя и предусматривает активность работника, направленную на достижение социально-профессионального статуса ради самого статуса или на процесс движения в организационной системе разделения труда ради самого процесса, т.е. функцию цели здесь выполняет либо определенная должность, либо сама деятельность по получению этой должности. Эта ориентация связана с жесткой конкуренцией за более выгодные условия профессиональной деятельности. Карьера в технократической модели делается благодаря не только профессиональному опыту и активности работника, но и протекционизму.

Адаптивный модус деловой карьеры характерен для банков с предпринимательской стратегией. Этот модус деловой карьеры позволяет банкам реагировать на процессы, происходящие во внешней среде, достигая компромисса между личностно-профессиональным позиционированием работников и статусно-должностным для удовлетворения потребительского спроса на труд. Это предполагает создание условий для овладения работником смежных профессий, освоения работы, выполнявшейся его коллегами, стоящими выше или ниже по иерархической лестнице, а следовательно, для механического перемещения работников с одних рабочих мест на другие внутри и вовне организации с учетом требований изменяющейся трудовой нагрузки.

Гуманистический модус деловой карьеры получил распространение в банках, придерживающихся стратегии прибыльности и циклической стратегии. Гуманистическая ориентация выражается в рассмотрении социально-профессионального окружения с точки зрения пользы, прежде всего для работников, что проявляется в их стремлении удовлетворять личные потребности (в том числе в сохранении здоровья, обеспечении своей материальной стабильности) через самосовершенствование, обучение новым технологиям, переподготовку, приобретение жизненного опыта, осуществляемого за счет профессионально-квалификационной и географической мобильности, смены круга общения, образа жизни в целом. Интересы отдельных работников превалируют над интересами организации. 
Исходя из сказанного выше, деловая карьера, наполняясь в современных условиях новым социально-экономическим содержанием, предстает как механизм взаимодействия профессиональной и организационной карьеры, а следовательно, личностно-профессионального и статуснодолжностного видов позиционирования работников на рынке труда, обеспечивающих изменение конкурентной позиции экономических субъектов в целях наиболее эффективного удовлетворения интересов в качестве трудовой жизни. Познание социально-экономического модуса деловой карьеры позволяет выявить специфические функции и регулятивные возможности каждого из видов карьерного позиционирования для достижения конкурентного превосходства на внутреннем и внешнем рынках труда, их связи с иными кадровыми явлениями и процессами, обосновать целесообразность определенных стратегических альтернатив деловой карьеры, провести мониторинг динамики взаимосвязи вида карьеры и конкурентоспособности каждого отдельного работника, персонала организации в целом.

\section{Лumepamypa}

1. Сотников Н.3. Деловая карьера как метамодель управления конкурентоспособностью наемного персонала // Вестник НГУЭУ. 2015. № 1. С. 190-200.

2. Миляева Л.Г. Диагностика развития профессиональной карьеры персонала в условиях реализации компетентностного подхода // Управление человеческим потенциалом. 2016. № 1. С. 52-58.

3. Бодалев A.А. Вершина в развитии взрослого человека, характеристики и условия достижения. М. : Флинта: Наука, 1998.

4. Зайцев Г.Г., Черкасская Г.В. Управление деловой карьерой. М. : Академия, 2007. 256 с.

5. Кибанов А.Я. Основы управления персоналом. М. : ИНФРА-М, 2015.

6. Силласте Г.Г. Гендерная асимметрия как фактор карьерного роста женщин // Высшее образование в России. 2004. № 3. С. 122-133.

7. Hall D.T., Mirvis P.H. The new career contract developing the whole person at midlife and beyond // Journal of Vocational Behavior. 1995. Vol. 35. P. 64-75.

8. Шиекторенко И.В. Социальные лифты в структуре социальной мобильности индивида // Управленческое консультирование. 2013. № 6 (54). С. 93-103.

9. Беляцикий Н.П. Методическое обеспечение карьерной политики предприятия // Менеджмент в России и за рубежом. 2010. № 3. С. 108-114.

10. Еремина И.Ю., Тодераш В.А. Управление карьерой в России и за рубежом // Проблемы экономики и управления нефтегазовым комплексом. 2016. № 2. С. 12-15.

11. Могилевкин E.A. Карьерный рост: диагностика, технологии, тренинг. СПб. : Речь, 2007.

12. London M., Moon E.M. Career management and survival in the workplase. San Francisco: CA : Jossey-Bass, 1987.

13. Noe R.A., Noe A.W., Bachuber J.A. An investigation of the correlates of career motivation // Journal of Vocational Behavior. 1990. Vol. 37, № 3. P. 340-356.

14. Сотникова С. Карьерная систематика: от личной конкурентоспособности к конкурентоспособности бизнеса // Кадровик: Кадровый менеджмент. 2010. № 9. С. 10-17.

15. Сотникова С.И. О карьерном пространстве в российском обществе // Известия Иркутской государственной экономической академии. 2014. № 3. С. 46-52.

16. Сотникова С.И. Управление карьерой персонала в системе менеджмента современной организации // Вестник Омского университета. Серия «Экономика». 2014. № 3. C. 60-67. 
17. Сотникова С.И. Методологические подходы к исследованию карьеры работника: возможности и ограничения // Вестник НГУЭУ. 2014. № 2. С. 142-154.

Sotnikov N.Z., Novosibirsk State University of Economy and Management (Novosibirsk, Russian Federation). E-mail: n.z.sotnikov@edu.nsuem.ru

\section{DIALECTICS OF BUSINESS CAREER OF BANK PERSONNEL: SOCIAL AND} ECONOMIC MODE

Keywords: Business career; social and economic mode; bank personnel; competitiveness of personnel; intensity of career.

In article results of scientific researches of processes of formation, development and destruction of business career in the bank organizations of Novosibirsk during 2010-2016 are considered. Business career, representing the complex, open and complete system of three substances (qualities of labor life of the worker, labor mobility and positioning in labor market), is backbone in modeling of competitiveness of human resources. As an object of research the way of functioning, a look and the nature of business career in commercial banks makes different development strategies. The research objective consists in identification of the social and economic regularities of a mode of business career caused by differences in a competitive position of the bank organizations. The hypothesis of a research consists that the social and economic mode of business career defines mechanisms of localization and the approval of competitive superiority both the worker, and the bank organization in a market situation. Knowledge of a social and economic mode of business career of bank workers has allowed to reveal existence of the social and economic conflict between professional career and organizational. Ways of resolution of conflict of business career form strategic alternatives of interaction of professional career and organizational, directed to maintenance and increase in competitiveness of human resources of the bank organization.

The business career acts as dialectic system which driving force and a source of development is emergence, formation and permission immanent to her the conflict between professional career and organizational, interorganizational and intra organizational. The mode of business career describes a way of permission of this conflict and is focused on preservation or improvement of a competitive position in labor market. In article it is proved that strategic alternatives of business career are limited and objectively set by the existing rules and status and role instructions characterizing the market stratified system of division of bank work. The mode of business career for banks with different development strategies is various. The author's tipologization of a social and economic mode of business career of workers depending on a way of resolution of conflict of business career is offered. Tipologization of a mode of business career creates a basis for identification and updating of specific functions and regulatory opportunities of each of types of career for improvement of a competitive position of the worker and the bank organization in labor market in interrelation with other personnel phenomena and processes.

\section{References}

1. Sotnikov N. Z. Delovaya kar'era kak metamodel' upravleniya konkurentosposobnost'yu nayomnogo personala // Vestnik NGUEHU. 2015. № 1. S. 190-200.

2. Milyaeva L. G. Diagnostika razvitiya professional'noj kar'ery personala v usloviyah realizacii kompetentnostnogo podhoda // Upravlenie chelovecheskim potencialom. 2016. № 1. S. 52-58.

3. Bodalev A. A. Vershina v razvitii vzroslogo cheloveka, harakteristiki i usloviya dostizheniya. M.: Flinta; Nauka. 1998.

4. Zajcev G. G., CHerkasskaya G.V. Upravlenie delovoj kar'eroj. M.: Akademiya, 2007. $256 \mathrm{~s}$.

5. Kibanov A. YA. Osnovy upravleniya personalom. M.: INFRA-M, 2015. 
6. Sillaste G. G. Gendernaya asimmetriya kak faktor kar'ernogo rosta zhenshchin // Vysshee obrazovanie v Rossii, 2004. № 3. S. 122-133.

7. Hall D. T., Mirvis P. H. The new career contract developing the whole person at midlife and beyond. Journal of Vocational Behavior, 1995 V. 35. pp. 64-75.

8. SHpektorenko I. V. Social'nye lifty v strukture social'noj mobil'nosti individa // Upravlencheskoe konsul'tirovanie, 2013. №6 (54). S. 93-103.

9. Belyackij N. P. Metodicheskoe obespechenie kar'ernoj politiki predpriyatiya. // Menedzhment v Rossii i za rubezhom. 2010. №3 . S. 108-114.

10. Eremina I. YU., Toderash V. A. Upravlenie kar'eroj v Rossii i za rubezhom // Problemy ehkonomiki i upravleniya neftegazovym kompleksom. 2016. № 2. S. 12-15.

11. Mogilevkin E. A. Kar'ernyj rost: diagnostika, tekhnologii, trening: monogr. SPb.: Rech', 2007.

12. London M., Moon E. M. Career management and survival in the workplase. San Francisco, CA : Jossey-Bass, 1987.

13. Noe R. A., Noe A. W., Bachuber J. A.. An investigation of the correlates of career motivation. Journal of Vocational Behavior. 1990. V. 37. 3. pp. 340-356.

14. Sotnikova S. Kar'ernaya sistematika: ot lichnoj konkurentosposobnosti k konkurentosposobnosti biznesa // Kadrovik: Kadrovyj menedzhment, 2010. № 9. S. 10-17

15. Sotnikova S.I. O kar'ernom prostranstve v rossijskom obshchestve //Izvestiya Irkutskoj gosudarstvennoj ehkonomicheskoj akademii. 2014. № 3. S. 46-52.

16. Sotnikova S.I. Upravlenie kar'eroj personala v sisteme menedzhmenta sovremennoj organizacii // Vestnik Omskogo universiteta. Seriya: EHkonomika, 2014. № 3. S. 60-67.

17. Sotnikova S.I. Metodologicheskie podhody $\mathrm{k}$ issledovaniyu kar'ery rabotnika: vozmozhnosti i ogranicheniya // Vestnik NGUEHU. 2014. № 2. S. 142-154.

\section{For referencing:}

Sotnikov N.Z. Dialektika delovoj kar'ery bankovskih rabotnikov: social'no-ehkonomicheskij modus [Dialectics of business career of bank personnel: social and economic mode]. Vestnik Tomskogo gosudarstvennogo universiteta. Ekonomika - Tomsk State University Journal of Economics, 2018, no 44, pp. 137-149. 